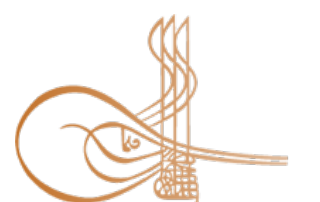

www.turkishstudies.net/economy
Turkish Studies - Economics, Finance, Politics

eISSN: 2667-5625

Research Article / Araştırma Makalesi

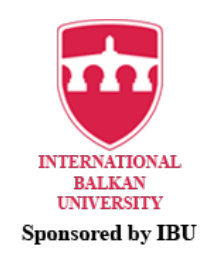

Sponsored by IBU

\title{
Yönetim Alanındaki Gelişmelerin Değişen Dünya Bağlamında İncelenmesi: Fordist ve Post- Fordist Sistem Özelinde Bir Değerlendirme
}

\author{
The Examination of Developments in the Field of Management within the Context of the Changing \\ World: An Evaluation on Specific to Fordist And Post-Fordist System
}

\author{
Bayram Kırmızıgül ${ }^{*}$ - Cihan Palanc1 ${ }^{* *}$
}

\begin{abstract}
People's lifestyles and cultures have changed since their existence on the world. These changes have survived through different phases with the effects of various factors. Each phase of these changes will be able to be evaluated separately under conditions specific to the period. However, until the industrial revolution, the stages of life styles and culture were spreading to very long periods. Traditions, interpersonal relations, social norms, methods of doing business and even the functioning systems of the states have been going on for a long time. With the industrial revolution, the intense industrialization that emerged in the next period, the productivity increases in the field of management along with the scientific approaches, the mass production with the fordist production system, and finally these globalizations, together with the globalization, have started to show accelerations that cannot be compared with the previous periods. Therefore, the spread of industrialization, the strengthening of enterprises and the development of management techniques with more effective results have become prominent factors in the change of people, societies and the world. In a sense, changes in the field of business and management have also paved the way for social changes. In this study, a detailed literature review has been made in specific to fordist system on how businesses and their management styles play a role in social changes in the world. Social changes that come forward as a result of these evaluations; dehumanization, mind-time-space standardization, the imposition of certain life patterns, the creation of new consumption habits, and the dissemination of mass culture.
\end{abstract}

Structured Abstract: It all started with a slight change in the production process. Until previously, while the production object was stable and workers were mobile; in this model, workers were moved with a fixed, production object band. The impact of this simple-looking change of the Fordist system had opened the door to a very complex and world-wide transformation. The Fordist system was organized on the basis of the detailed division of labor called "Taylorist scientific method", and was directed to provide productivity increase through

*Dr. Öğr. Üyesi, Munzur Üniversitesi, Pertek Sakine Genç Meslek Yüksekokulu, Turizm ve Otel İşletmeciliği Bölümü Asst. Prof. Dr. Munzur University, Pertek Sakine Genc Vocational High School, Department of Tourism and Hotel Managemet

ORCID 0000-0002-9451-5384

bayramkgul@hotmail.com

** Dr. Öğr. Gör., Munzur Üniversitesi, Pertek Sakine Genç Meslek Yüksekokulu, Finans Bankacılık ve Sigortacılık Bölümü

Dr. Lecturer, Munzur University, Pertek Sakine Genc Vocational School, Department of Finance Banking and Insurance Department

ORCID 0000-0001-6766-3691

cihanp44@gmail.com

Cite as/ Atıf: Kırmızıgül, B. \& Palancı, C. (2020). Yönetim alanındaki gelișmelerin değișen dünya bağlamında incelenmesi: fordist ve post-fordist sistem özelinde bir değerlendirme. Turkish Studies - Economy, 15(2), 843-853. https://dx.doi.org/10.29228/TurkishStudies.41767

Received/Geliş: 14 February/Şubat 2020

Accepted/Kabul: 20 June/Haziran 2020

Checked by plagiarism software

Copyright (C) INTAC LTD, Turkey 
a process that every worker was defined in a narrowly defined manner and performed a routine job continuously. Production is carried out on a continuously shifting production line using highly specialized, single-purpose machines and uneducated, unqualified workforce. This line, in which a constant relationship is established between the machine and the worker, coordinates the different rhythms and different processes, allowing the standardization of the output, which provides the technical conditions of mass production. Therefore, workshops producing on a large scale become basic units. A similar form of production was applied before Henry Ford. For example, at the end of the 19th century, the first trials of mass production were made in animal slaughtering and meat packaging business or in bicycle production in the 1890s, but it was Henry Ford who made this production institutional and scientific.

This success of the Fordist system - despite its internal contradictions - was not enough to prevent the 1929 crisis due to the impact of the World War II and the difficulties in planning. Mass production was initiated thanks to Fordism, there was a huge increase in production, but the overproduction (or under-consumption) crisis broke out in the 1930s as there were no regulatory institutions to provide mass consumption. For this reason, new monopolistic regulatory institutions began to emerge in the period of World War II and beyond, which can meet the needs of the intensive accumulation regime. After the d World War II, Fordist system, which renewed itself with monopolistic regulations and intense accumulation regime, achieved a very stable and high growth pace until 1970s. The prosperity and democracy created by the Fordist accumulation regime were replaced by another crisis and new criticisms in the 1970s. This problem can be dealt with in the context of both the internal contradictions of the Fordist system and the general conjuncture of the world. This internal contradiction is considered as "rigidity" in one word, that is, the system's inability to show sufficient flexibility in response to changing consumer demands.

In the transition period to postfordism, it is on the agenda that states experience some basic transformations. Under this lies the desire to secure the ability to innovate and change in capitalist relations of production through the creation of new public tasks and political spheres. The importance of change ability and innovative entrepreneurship is reflected in a number of public strategies, among which we can count technology and structural policies. This new policy approach, which focuses on global competitiveness, is seen as the end of the demand-oriented Keynesian Welfare State that manages with macroeconomic policies. The peculiarity of the Keynesian Welfare State was its ability to control international economic relations and the redistribution of social products to a large extent. However, after the 1970s, the characters and functions of the Keynesian Welfare State, which was built after the World War II, were subjected to some fundamental transformations.

In this study, it has been examined how and to what extent the changes occurring in the social life and therefore in the world have been affected depending on the developments in the field of business and management since the transition from the industrial revolution to the information society has been examined, and some findings have been made by evaluating these data in the light of these data. was obtained. The results obtained in accordance with the purpose of the study are listed below:

- The motto of obtaining the most output with the least input underlying the scientific management approaches, that is, increasing the efficiency, has reached the highest level in the fordist system. In this new process, the place of the employees within the enterprises has become one of the factors of production by becoming the subject of the production and the employees have become an object in the system. In other words, the employees are divided into classes according to their skills and qualifications in terms of their bosses and managers, and this classification has been found in the social sense and a dehumanization situation has emerged.

- Doing the most work with the least energy spent by management approaches and fordist production system and doing this in the fastest and most accurate way has found a response in social life. The person who designed himself on this basis in the business life had to adopt a standardized mind or thought system that thinks more pragmatically in every area of daily life and puts it at the center of life.

- Enterprises had to develop shift-based working systems not only in the daytime but also in the evening and at night in order to produce faster responses to the needs of the society by producing more in shorter periods. These developments have led to the regulation that life can be lived as well as during the day and at night, and that life can continue for 24 hours, and it has become inevitable to standardize the time again and on a different level by making every hour of the day livable and workable.

Turkish Studies - Economy, 15(2) 
- With the emergence of management as a science and subsequent large-scale enterprises producing mass production based on the Fordist production system, small businesses that were previously located close to the houses have now started to be located in separate regions from the houses. Therefore, business life has evolved from daily life to an isolated quality. With mass production, businesses and factories have started to turn to standard designs for producing large amounts of goods and services of the same type. This spatial standardization in businesses and factories has found a response in social life over time, and it has begun to conceptualize in areas such as residential areas, entertainment venues or leisure areas, and standardization at certain levels according to the concepts created.

- The fact that the Fordist system produced mass production by increasing productivity in production made it impossible to meet human needs in a sense. Previously, standard models were produced in certain size ranges for individuals who went to tailors and made clothes according to their body sizes. As a way of eliminating this negative side of mass production, new consumption habits were introduced to the communities, and mass consumption became dominant. Now, people have begun to turn to products that are designed to meet the general needs optimally, but are more affordable and affordable in terms of price and quality.

- The fact that the daily living standards of people based on habits that will not negatively affect the productivity of their working areas, and on the contrary, contribute to the smooth running of the capitalist system, has been among the effects of operators and managers on the new social structure. The human model, which will spend most of its time in non-business life at home and wake up to work the next day at a better performance level, is a desirable situation for businesses or capital owners, and new behavior patterns and life models for employees who have a professional work life.

- Another effect that enterprises spread to the changing world in order to sustain their existence within the capitalist order is the creation of mass culture. In this way, it is aimed to direct the societies to similar consumption patterns by transforming them into cultures that are shaped and differentiated according to certain classes, and to bring the workers belonging to each class to work and working conditions so as to have a income and free time that can use the mass-produced goods and services produced.

Keywords: Management, Fordism, Globalization, Mass Culture

Öz: İnsanların yaşam biçimleri ve oluşturdukları kültürler, dünya üzerinde varoluşlarından itibaren değişimler göstermiştir. Bu değişimler çeşitli faktörlerin etkileri ile farklı evrelerden geçerek günümüze ulaşmıştır. Yaşanılan değişikliklerin her bir aşaması, döneme özgü koşullar altında ayrı ayrı değerlendirilebilecektir. Ancak sanayi devrimine kadar, yaşam biçimleri ve kültürel değişimde yaşanan evreler çok uzun dönemlere yayılmaktaydı. Gelenekler, kișilerarası ilișkiler, sosyal normlar, iș yapma yöntemleri ve hatta devletlerin ișleyiș sistemleri uzun süreler boyunca belirli seyirlerde devam etmekteydi. Sanayi devrimi ve daha sonraki dönemde gerçekleşmiş olan yoğun sanayileşme, ortaya çıkan yeni bilimsel yaklaşımlar, bunları takiben fordist üretim sistemiyle gelişen seri üretim ve son olarak da küreselleşme ile birlikte yönetim alanındaki üretkenlik önceki dönemlerle karșılaştırılamayacak düzeylerde ivmeler göstermiștir. Dolayısıyla endüstrileșmenin yayılması, işletmelerin güçlenmesi ve yönetim tekniklerinin daha etkili sonuçlar verecek şekilde gelişmesi, insanların, toplumların ve dünyanın değişiminde oldukça belirleyici faktörler olarak öne çıkmış durumdadır. Bir anlamda, işletmecilik ve yönetim alanındaki değişiklikler de sosyal değişimlere zemin hazırlamış olduğu söylenebilmektedir. Bu çalıșmada, literatür taraması yapılarak, işletmelerin ve onların yönetim biçimlerinin dünyadaki sosyal değişimler üzerinde nasıl roller oynadığının, fordist üretim biçimi özelinde ayrıntılı olarak değerlendirmesi yapılmıştır. Yapılan bu değerlendirmeler neticesinde öne çıkan sosyal değişimler; dehümanizasyon, akıl-zaman-mekân standardizasyonu, belirli yaşam kalıplarının dayatılması, yeni tüketim alışkanlıklarının oluşturulması ve kitle kültürünün yaygınlaştııılması başlıkları halinde sonuç bölümünde aktarılmıştır.

Anahtar Kelimeler: Yönetim, Fordizm, Küreselleşme, Kitle Kültürü 


\section{Giriş}

Her şey aslında, üretim sürecinde çok küçük bir değişimle başladı. Öncesine kadar üretim nesnesi stabil, işçiler hareketli iken bu modelde işçiler sabit, üretim nesnesi bir bant ile hareketli k1lınmıştı. Fordist sistemin bu basit gibi duran değişiminin yarattığı etki, oldukça karmaşık ve dünya ölçeğinde büyük bir dönüşümün kapılarını açmıştı. Yentürk'ün bütüncül tanımlaması ile: "Fordist sistem; "Taylorist bilimsel yöntem" olarak adlandırılan ayrıntılı işbölümü esasına göre örgütlenmiş, her işçinin dar anlamda tanımlanmış, rutin bir işi sürekli olarak yaptığı bir işleyiş ile verimlilik artışı sağlamaya yönelmiştir. Son derece özel, tek amaçlı makineler ve eğitimsiz, niteliksiz işgücü kullanarak üretimin sürekli kayan bir üretim hattı üzerinde yapılması söz konusudur. Makine ile işçi arasında sabit bir ilişkinin kurulduğu bu hat, farklı ritim ve farklı işlemleri koordine ederek çıktının standartlaşmasına elvermekte, bu da kitle üretiminin teknik koşullarını sağlamaktadır. Bu nedenle de büyük ölçekte üretim yapan atölyeler temel birimler olmaktadır" (Yentürk, 1993: 43-44). Henry Ford öncesi de benzer üretim biçimi uygulanmıştır. Örneğin; 19. Yüzyılın sonunda hayvan kesimi ve etlerin paketlenmesi işinde ya da $1890^{\prime}{ }^{\prime} 1$ yıllarda bisiklet üretiminde seri üretimin ilk denemeleri yapılmış fakat bu üretimi kurumsal ve bilimsel hale getiren Henry Ford olmuştur (lean.org.tr). Yukarıdaki tanımda da geçen bilimsellik ve kurumsallık mefhumlarının gerek kuramsal gerekse uygulamaya dönük karşılıkları aynı zamanda, Taylor ve Weber' in yaklaşımlarında da görülmektedir. Harvey'in de altını çizdiği üzere, fordist sistemin sembolik başlangıç yılı 1914 olarak kabul edilse de, Taylor 1911 yllında yayınlanan the principles of scientific management adlı çalışmasında; her emek sürecinin bölümlere ayrıştırılması yani etkili bir iş bölümünün yapılması ve bu işlerin hareket ve zaman araştırmasının standartlara uygun olarak düzenlenmesi durumunda üretkenliğin nasıl artacağını anlatmıştır. Fakat Ford'u Taylor'dan farklı kılan şey, onun yönetim ve verimlilik üzerine ortaya koyduğu düşünceleri yeniden yorumlaması ve bu yeniden yorumlama üzerine inşa ettiği kendine has vizyonu olmuştur. Ford, kitle üretimini, kitle tüketimini, üretimde emeğin işlevini yeniden belirleyen yeni bir sistemi, emeğin denetimi ve yönetiminde yeni bir politikayı ve aslında estetikten psikolojiye ve tüm toplumsal süreçlerde yaşanacak -rasyonelleştirilmiş, popülist, erekseldeğişimleri görmüştü (Harvey, 2003: 147-148).

Taylor bilimsel yönetim anlayışının prensiplerini oldukça basit ve anlaşılır bir biçimde ifade etmiştir. Dikmen'in de ifade ettiği gibi, aslında, işletme bilimi içerisinde devrim yaratan tüm yenilikler genel olarak çok komplike bir mantık silsilesinden ziyade, daha basit ve anlaşılır kuramsal temellere dayanmaktadır. Belirli bir işin en kolay yoldan, en doğru şekilde ve en hızlı biçimde yapmanın bir tane yolu vardır. Taylor'un ortaya koyduğu da esasen budur:

“...O, bir kronometre kullanarak, işleri incelemiş, iş nasll yapılırsa, hangi yöntemle ve hangi araçlar kullanilırsa ve hangi hareketler yardımıyla yapılırsa en hızlı biçimde sonuç alınır sorusunu bulmaya soyunmuştur... Taylor'a göre bir işi yapmanın en kolay tek bir yöntemi vardır. Mühendisin görevi de bu en kolay ve en hizlı tek yolu bulup bunlart işçilere ögretmektir. Burada Taylor, üç temel etkinlik çerçevesinde işlerin yapılış biçimlerini yeniden örgütler: 1- İşsin standartlaşması 2- İşin basitleş̧tirilmesi 3- İşin tanımlanması...” (Dikmen, 2015: 88).

Yukarıda bahsedilen temel ilkeler çerçevesinde yapılan şey, üretim araçlarının veya bütün bir işletmenin yeniden yapılandırılması değil; emeğin ve iş yapma usullerinin en yüksek verimi alabilecek biçimde yeniden örgütlenmesidir. Belek de bu duruma dikkat çekerek; Taylorizm'in temel ilkelerinin ortaya koyduğu anlayışı şu şekilde ifade eder: 1- Üretim sürecinin parçalara ayrılması neticesinde emeğin basitleştirilmesi ve dolayısıyla emeğin vasıfsızlaştırılması, 2- Emek sürecinin dehümanize edilmesi: Bireyin çalışmasının üretimin bütününden izole edilmesi, sistemin merkezileşmesi ve zihinsel-bedensel emeğinin tamamen ayrışması. 3- Her işin planlanması ve aktarımı (Belek, 1999: 57). Taylor'un yönetim anlayışının bir başka önemli özelliği de "dehümanizasyon" süreci ile bağlantılı olarak, tek güdüleyicinin ücret olduğu gerçeğidir. Bu anlayış, sonraki dönemlerde neo klasik anlayış tarafından bu yönü ile eleştirilmiş ve başta Taylor olmak üzere 
Fayol ve Weber'in sonradan klasik yaklaşımlar olarak literatüre geçecek olan yönetim yaklaşımlarına, psikolojik ve sosyolojik faktörler de ilave edilerek farklı güdüleyici perspektifler dolaşıma sokulmuştur (Tunçer, 2010: 85-86).

Taylor'un üretimde verimliliği arttıracak olan teorisi, yönetsel anlamda karşılığı Fayol tarafindan planlama, örgütleme, yürütme, koordinasyon ve denetlemeden oluşan bir süreç olarak, Weber tarafından ise bürokratik kural ve kaideler olarak işlenmiştir. Bürokratik Yönetim Anlayışı, verimlilik artışının sağlanabilmesi için odağını, üretimden yönetime kaydırır ve sacayağını tamamlar. Dikmen'in Weber'den aktardığı üzere; çağdaş bürokrasi, "yasalar ve yönetmeliklerce düzenlenmiş belirli bir yetki alanı ilkesi" dir. Dikmen bu rasyonel iktidarı yine Weber'den şu alıntıyla açılımlar: "iktidarın ve otoritenin yasalar ve kurallar nezdinde soyutlanması ve bu kuralların bir sultan bir prens bir kral ya da tanrıya gerek duyulmaksızın, kendiliklerinden ama çağdaş kurallar temelinde örgütlenme üstünlüğüne ulaşmış modern insan sayesinde egemenlik alanına kavuşacak..." (Dikmen, 2015: 66). Weber Bürokratik Yönetim Anlayışını, sadece devlet yönetimi ya da işletmeler üzerinden değil tüm toplumsal örgütlenmenin merkezine yerleştirmeyi önerir. Aydınlanma ile başlayan rasyonalizasyon sürecinin belki de en doruk noktası Weber'in teorisidir. Köse ve Öncü'nün imlediği gibi, nesnel aklın en üste yerleştirildiği ve rasyonalizasyon öncesi kurulan tahakküm ilişkilerinden kurtulmanın biricik yolu olarak bürokrasi yaklaşımı, aynı zamanda tikel öznenin akıl-duygu durumunu ikinci plana itmiştir. Buna göre, Köse ve Öncü Weber dolayımı ile modern dünyanın artık "kişilere göre değişmeyen" bir örgütlenme ile insanları bir arada tutmaya zorladığını ve modern dünya içinde sevgi, nefret gibi duygulara yer olmadığını söyleyerek, modern kapitalizmin insanlar arası ilişkilerin hesaplanamazlığı, yani duygusal öğeleri ayıklama adına örgütlendiğinin altını çizerler. Dolayısıyla aslında yapılanın "salt öznel olan her şeyin devre dışı bırakılması" olduğudur. Böyle bir durumda doğal olarak, insani duyguları bir kenara bırakabilmiş "nesnel" uzmana gerek duyulacağı gerçeği açığa çıkmıştır (Köse ve Öncü, 2000: 41). Weber'in teorisinde, katı bir hiyerarşi ile en ince noktasına kadar tanımlanmış iş akışı ve bu akışın denetlenmesi süreci tanımlanmakta iken, aynı zamanda bürokrasi içinde yazılı belge ve iletişimin örgütün işleyişi için hayati önem taşıması gerçeğini ve buna bağlı olarak da ast-üst ilişkisinin olabildiğince "dilin öznelliğinden" kurtarılarak yazının nesnelliğine bırakılması zaruretini birçok yazar paylaşır.

Gerek Ford'un kitlesel üretim modeli ve gerekse Taylor, Fayol ve Weber'in, "yüksek ihtimalle birbirlerinden haberleri olmadan" oluşturdukları teoriler aslında dönemin bir zorunluluğu ve ortak ruhunu yansıtmaktadır. Çünkü kapitalizm artık kurumsallaşmış ve üretim-verimlilik arasındaki ilişkiyi farklı bir perspektifte kurmaya başlamıştır. Fakat Belek'in de vurguladığı gibi, Ford, yönetim ve üretim konusunda sahip olduğu vizyon ile yapılacak olan kitlesel üretimin, yine kitlesel manada tüketim olarak karş1lı bulabilmesi için başka bir toplumsal formasyon ve tüketim alışkanlığının oluşması gerektiğini daha net ön görebilmiştir. Belek, Taylorizm'in emeğin makine başındaki örgütlenmesini; Fordizm'in ise emekle birlikte makineli sistemin fabrika içindeki yeniden yapılanma sürecini dizayn ettiğinin altını çizmektedir. Belek özellikle iktisadi ve ekonomik düzlemde Fordizm'in Taylorizm'den daha anlamlı neticeler ortaya koyduğunu belirterek, Fordizm'in yalnızca yönetim ve üretim süreçlerinde yaşanan dönüşümle sınırlı kalmayan ve fakat bunlara ilaveten üretim ve tüketim kalıplarının yeniden şekillendirilmesi, dolayısıyla da piyasanın yeniden regülasyonu ve sonuç olarak toplumsal bir dönüşümü de kapsayan daha geniş bir çerçevedeki etkilerine dikkat çekmektedir (Belek, 1999: 60).

Dikmen (2015: 97-104)'e göre, işletmecilik alanında yönetim ve üretim üzerine yapılan bu çalışmalar aslında üzerine uzun süre düşünülmüş, deneysel çalışmalarla araştırılmış ve ispatlanmış ve bir anlamda derin bir rasyonalizasyon sürecine tabi tutulmuş standardizasyon çalışmaları bütünü olarak özetlenebilmektedir. Dikmen'e göre bu standardizasyonlardan ilki aklın standardize edilmesidir. Bu kavramsallaştırmayla anlatılmak istenen; inceleyerek, ölçerek, araştırarak, daha az enerji ama daha yüksek hız ve verimlilikle çalışan aklın, en önemli unsur olarak değer kazanmasıdır. $\mathrm{Bu}$ standardizasyonun işletmecilik alanındaki manası da verimlilik artırma çabalarının yönetimde en 
kritik yeri tutması olarak değerlendirilebilecektir. Bu durum bir anlamda yaşamın içindeki her şeye meta ya da nesne olarak bakma şeklinde anlamlandırılabilecektir. Modern yönetimin en temel mefhumu; verilen işi yerine getiren, çalışan ile çalışanın yaptığı görevi izleyen, aksaklıkları anlamaya çalışan, işi hızlandırmak için yeni teknikleri geliştirip bunu çalışan üzerinde deneyen, dolayısıyla iktidarını bilimsel bilgi ve teknoloji ile rasyonalize eden bir süreç olarak tanımlanabilir. Bu aynı zamanda hiyerarşinin imlenişidir. İkinci olarak ise zamanın standardizasyonu vurgulanmaktadır. Fizik terminolojisinde göreli bir kavram olarak ele alınan zaman, gündelik yaşam içerisinde işlevsel bir niteliğe kavuşacak biçimde, mekanik saatin icadı ile beraber eşit aralıklara bölünerek standartlaştırılmıştır. Sanayi devrimi ve onunla beraber ortaya çıkan makineleşme zamanın standardizasyonunu ve dolayısı ile saatin önemini kaçınılmaz kılmıştır. Bütün bir yaşamı standart aralıklarla bölümlendirip bu bölümlerden her birinden yüksek verimlilik elde etme çabası modern insanın kendisini ve dünyayı yeniden kurma çabasına dönüşmüştür. Bu çaba ile insan geceleri de gündüz gibi değerlendirmeye ve işlerin bir bölümünü gece vardiyasına taşıyarak verimliliği artırma arayışına yönelmiştir. Modern iş anlayışı bu açıdan değerlendirildiğinde bir yönüyle de kronometrenin zaferi olarak düşünülebilecektir. Hangi işin ne zaman yapılacağı, işin yapılma sürecinin ne kadar kısalacağ 1 , kaç saat çalış1lıp ne kadar süre mola verileceği kronometreye bağlı olarak ayarlanmaktadır. Üçüncü standardizasyon aşaması da mekânın standardize edilmesidir. Sanayi devrimini takiben yaşam alanlarıyla çalışma alanları birbirinden izole edilmiş, büyük kentler bu anlayışa göre farklı bir konsepte bürünmüştür. Atölyeler, işyerleri ve fabrikalar verimlilik esasına göre en ince ayrıntısına kadar hesaplanarak tasarlanmış; ergonomi disiplini, alet, makine ve çalışma alanlarının insanların en iyi ve en hızlı çalışabileceği şekilde düzenlenmesi gayesiyle aktive edilmiştir.

Dikmen'in oldukça sağlam gerekçelere dayandırarak ve net bir biçimde açıkladığı bu standardizasyon süreci aslında bir anlamda yönetim ve üretim tekniklerindeki gelişmelerin bir neticesi olarak varlık bulmuştur. Ancak yönetim ve üretim sürecinin bir anlamda dayattığı bu standardizasyon olgusu, gündelik hayatta da tüketimin standardizasyonu ve dolayısıyla belli bir yaşam tarzının standardizasyonunu da dayatmıştır. Zira tüm bu üretim-yönetim süreci ve her ikisindeki yüksek standartlaşma yeni bir yaşam biçimini ve tüketim kültürünü gerektirmektedir. (Harvey, 2003: 148)'de ifade ettiği gibi, Ford'u ayırıcı kılanın da gerek yaşanmakta olanları ve gerekse yaşanacak olanları ön görebilmiş olmasıdır. Ford yeni bir tüketim kültürü ve yaşam biçimi oluşturma denemelerini önceleri kendi fabrika işçilerine uygulamış, sonrasında bu bir makro kültür politikası olarak tüm Avrupa ve Amerika'da örgütlenmiştir. Harvey, Roosevelt'in New Deal ile yapmaya çalıştığı kapitalizmi kurtarma çabasını, Ford'un döneminde tek başına yapmaya çalıştığına dikkat çekerek, durumu şu şekilde izah etmiştir:

"Ford, yeni bir toplum yaratmanın büyük şirketler aracıllğıyla olacağını öngörmüştür. Bu çerçevede sekiz saatlik, beş dolarlık işgünüyle hedeflenen şey sadece işçinin son derece üretken montaj hattına adapte olmasını sağlamak değil; aynı zamanda işçilerin şirketler tarafından piyasaya sürülen malları alabilmesi için yeterli gelire ve boş zamana sahip olmalarını da sağlamaktı. Ford bu amaçla 1916'da "yeni insan" figürünün sermayenin ihtiyaçlarına uygun olabilmesi için ahlaki bakımdan dürüst, iyi bir aile hayatına sahip, alkol tüketmekten kaçınan, yani rasyonel bir tüketim kalıbına uygun davranışlar sergileyebilmesini sağlamak üzere işçilerin evlerine sosyal hizmet uzmanlarl göndermiştir" (Harvey, 2003: 148-149).

Fordist sistemin bu başarısı -kendi iç çelişkilerine rağmen- II. Dünya Savaşı'nın etkisi ve planlamalarda yaşanan sıkıntılardan dolayı 1929 krizine engel olmaya yetmemiştir. Gelinen noktada klasik iktisat kuramının temel öğretilerinden biri olan "her arz kendi talebini yaratır" yaklaşımı ve bu çerçevede yapılan yoğun üretim, tüm çabalara rağmen tüketimde karşılık bulmamış ve eritilmesi mümkün olmayan büyük stoklar yaratmıştır. Taymaz da benzer bir bakış açısıyla içinde bulunulan durumu şöyle ifade etmiştir: 
"Fordizm sayesinde kitlesel üretime geçilmiş, üretimde büyük artı̧̧lar yaşanmış fakat kitlesel tüketimi sağlayacak düzenleyici kurumlar olmadığı için 1930 'larda aşırı-üretim (veya eksik-tüketim) krizi patlak vermiştir. Bu nedenle II. Dünya Savaşı ve sonrası dönemde, yoğun birikim rejiminin gereksinimlerini karşılayabilecek yeni tekelci düzenleme kurumları oluşmaya başlamıştır. II. Dünya Savaşı sonrası, tekelci düzenlemeler ve yoğun birikim rejimi ile kendini yenileyen Fordist sistem 1970 'lere kadar oldukça istikrarlı ve yüksek bir büyüme temposu yakalamıştır." (Taymaz, 1993: 21).

Kriz sonrası süreçte Fordist sistemin yeniden güçlenmesine etki eden faktörlerden birisi de dünyada hâkim iktisadi görüş haline gelen Keynesyen ekonomi modelidir. Klasik liberal iktisadın aksine Keynes, ekonomide esas lokomotifin arz değil talep olduğunu vurgulamıştır. Ekonomiye özellikle durgunluk dönemlerinde müdahale etmek gerektiğini, müdahale etmemenin krizi daha da derinleştireceğini ve bu müdahalenin de devlet eliyle yapılması gerektiği fikri Keynesyen ekonomi modelinin merkezinde yer almaktadır. Keynesyen yaklaşımın kabul görmesi ve ilkelerinin uygulanmasına bağlı olarak, devlet artık ekonominin en önemli aktörüdür. Devlet talep yaratacak önlemler almalı, -devlet harcamalarının arttırılması yolu ile- istihdam yaratmalıdır (Ertek, 2009: 67). Keynes'in ifadesi ile gerekirse devlet işçisine boş çukurlar kazdırıp, sonra tekrar aynı çukurları doldurtup onlara bu işin karşılığında bir ücret vermelidir (www.gutenberg.org). Bu devletin adı refah devletidir. Refah devletinin ilk uygulamaları 1930'larda başlamış ve oldukça başarılı olmuştur.

\section{Kitle Kültürü}

Yukarıda bahsedilen ve üretim sürecinde yaşanan değişimlerin kültürel üst yapıdaki karş1lığ1, Oskay (2000)'ın belirttiği gibi "kitle kültürüdür". Buna göre, üretim ilișkilerindeki bu dönüşüm, kitle kültürünü bir yandan kaçınılmaz kılarken, diğer yandan da ikinci bir işlev olarak kapitalizmin yeni ideolojik aygıtı haline getiriyordu. Şan ve Hira'nın ifade ettiği gibi, kavramın ortaya çıkışı Frankfurt Okulu referanslıdır. En başta kitle kültürü olarak adlandırılmasına rağmen, kavramın içi kapitalizmin sistematiği gereğince sonradan Frankfurt Okulu üyeleri Adorno ve Horkheimer tarafından kültür endüstrisi olarak revize edilmiştir. Kültür endüstrisinin mantığı; eğer kitlesel ya da Fordist üretim yapılıyorsa bu ürünlerin tüketimi de kitlesel olmalıdır şeklindedir. Dolayısıyla burada sınıfsal, sosyal, etnik her türlü başkalığın ortadan kaldırılması gerekir. Ortak bir kültür çerçevesinde herkesin aynı ürünleri tüketmesi şarttır. Yine Şan ve Hira'nın Marcuse ve Çağandan aktardığı gibi, Frankfurt Okulu geleneği, kültür endüstrisi kavramını 19. Yüzyılın sonu ve 20. Yüzyılın başlarında Amerika ve Avrupa'da yükselmeye başlayan eğlence endüstrisinin kültürel biçimlerinin metalaşmasını vurgulamak amacıyla kullanmışlardır. Söz konusu düşünürlere göre, eğlence endüstrisinin yükselmesi kültürel ürünlerin standartlaşması ve rasyonalizasyonu ile sonuçlanmıștır. Üretilen bu kültürel veya sanatsal ürünler kapitalist birikim ve kâr elde etme amaçlarına uygun olarak kitlelerin tüketimi için hazırlanmıştır. Bu ürünler, tüketici bireye bir yaşam biçimi, bir dünya görüşü benimsetir, şartlandırır ve değişik toplum sınıfları içinde çok sayıda insan tarafindan benimsenir duruma geldikleri zaman, reklam değerleri bir yaşam biçimi yaratır. Böylece tek boyutlu düşünce ve davranışlar biçimlenmiş olur (Şan ve Hira, 2007: 6).

Kitle kültürünün özü belirtildiği gibi "aynılaşma” dır. Bu aynılaşmaya Oskay da dikkat çekerek şunları söyler: "Kitle kültürü, yöneten ile yönetileni, varlıklı ile yoksulu özgür olan ile olmayanı, mutsuz insan ile onu mutsuz kılan toplumsal realiteyi özdeş kılacak bir yanılsama oluşturma işleviyle üretilir." Oskay ayrıca kitle kültürünün ürünlerinin biz tüketicilerin dışındaki işletmeler-kuruluşlar tarafından tasarlandığını bu süreçte bizim pozisyonumuzun edilgen olduğunu, bizlerin sadece endüstri aktörlerinin kafasındaki potansiyel müşteriler olduğumuzu savunmaktadır (Oskay, 2000: 152). Aynılaşmanın başka bir boyutu zaman konusunda gerçekleşmiş ve 18.19. yüzyıldaki vahşi kapitalizm dönemlerinde geçerli olan mantık, yani işçinin daha çok çalışması ve yoğun emek sömürüsü üzerinden artı değer yaratmak fikri, refah devleti uygulamalarınca ve kitle kültürünün gereği olarak yerini herkese boş zaman (leisure time) yaratma fikrine bırakmıştır. Önceden değinildiği gibi Ford aslında bunu kendi fabrika ölçeğinde yapmaya çalışmıştır. Fakat refah 
devleti uygulamaları ve sınıf direnci kaynaklı olarak gerçekleşen kurumsallaşma ile beraber işçiler artık daha makul sürelerde çalıştırılmaya ve tüketim yapabilmeleri adına da yeterli sürelerde boş zaman kullanma imkânı bulmaya başlamışlardı. Oskay'ın deyimi ile ortaya çıkan bu yeni durumun ad1 "tüketimin demokratikleşmesidir". Oskay bu demokratikleşmenin, kapitalist sistem ve egemenler tarafından önceleri tereddütle karşılandığını; çünkü çalışanların boş vakitlerinde tüketim dışı sınıfsalsendikal yani sistem karşıtı etkinlik ve örgütlenmeler içinde olabileceklerini düşündüklerini fakat var olan hedonistik tüketim etiğinin çalışan kesimlere de aşılanması gerekliliği fikrinin sonraları ağır bastığını ifade eder (Oskay, 2000: 189-190).

\section{Fordizmin Bunalımı ve Post- Fordizm}

Fordist birikim rejiminin yarattığı refah ve demokrasi 1970'lere gelindiğinde yerini başka bir krize ve yeni eleştirilere bırakıyordu. Bu sorun temelde, hem Fordist sistemin kendi iç çelişkileri ve hem de dünyanın genel konjonktürü bağlamında ele alınabilmektedir. Saklı, Fordizmin iç çelişkisini tek kelimelik ifadeyle "sertlik" (rigity) olarak, yani sistemin değişen tüketici taleplerine karşılık yeterli düzeyde esneklik gösterememesi hali olarak değerlendirmiştir. Ona göre, kitlesel ve yoğun üretim yapan işletmelerin ve bu işletmelerde sergilenen emeğin nitelik bakımından değişen koşul ve taleplere karşı yeterli tepkiyi ortaya koyamaması ve esnek üretim yapma imkanlarına sahip işletmelerin daha rekabetçi pozisyonlara ulaşması, Fordist üretim tarzını sürdürmekte olan işletmelerin dar boğaza girmesinin temel nedenini oluşturmaktadır (Saklı, 2007: 7). Argın'da (1992), benzer şekilde fordizmin en temel iç çelişkisini "esneksizlik" olarak ifade etmiş ve fordizmin postfordizme geçişinde bu geçişi farklı noktalardan okuyan ekollerin ortaklaştığı noktanın, hem işlev hem de katı otoriter iş sınıflandırılmasının esnekleşmesi ve daha yatay bir görünüm almaları olduğunu öne sürmüştür.

Daha mikro ölçekli ve salt işletmecilik açısından ele alınan bu yaklaşımlara ilaveten, daha büyük ölçekteki makro koşulların fordist sistemin yaşadığı krize etkileri de ayrıca ele alınmasını gerektirmektedir. Zira ortaya çıkan bu krizin üç temel nedeni olduğu görüşü ağırlık kazanmaktadır: Bunlardan ilki; refah devleti olarak daha önce de bahsedilen yaklaşımın çalışma hayatı, tasarruf etme, yatırım yapma gibi hususlarda ekonomik piyasada olumsuz etkiler yarattığı düşüncesidir. Bu durum literatürde "market distortion" olarak ifade edilmektedir. İkinci neden olarak da nüfusun giderek yaşlanması ve bu durumun uzun vadede yaşatacağı çarpıcı ve dramatik olumsuz neticeler olarak gösterilmektedir. Üçüncü neden olarak ise; hükümetlerin aşırı düzeylerde sosyal harcamalar yaparak savurgan politikalar izlemesi ve ortaya çıkan küresel sistemin rekabet gücü zayıf işletmeleri çıkmaza sokan sonuçları düzleminde ele alınmaktadır (Buğra ve Keyder, 2008: 56). 1970'lerde başlayan kriz ve stagflasyonu, refah devleti uygulamalarına bağlayan yaklaşımlar o dönem için oldukça kabul görmüştür. Genel olarak eleştiri, sosyal devlet harcamalarının vergiler üzerindeki olumsuz etkisi ile sosyal güvenlik sisteminin insanların tasarruf ve yatırım yapma güdülerini yok ettiği üzerineydi. Dolayısıyla yapılması gereken şey, devletin ekonomiye müdahalesini minimize etmek olmalıydı (Alp, 2009: 269).

Değişen taleplere cevap verebilme ve müşteri odaklılı̆̆ının yeni değer olarak ortaya çıkmasında dolayısıyla esneklik kavramının dolaşıma girmesindeki en önemli etken kuşkusuz bilgi teknolojilerinde yaşanan gelişmelerdir. Aydınlı'nın da içinde olduğu çoğu yazar, Fordist üretimin sonlanması ile yeni bir çağa, bilgi çağına girildiğini savunur. Fordist üretimin katı-değişmez üretim süreci ve emek yapısı, bilginin kullanılması ile başka bir forma dönüşmüştür. Aydınlı'nın Drucker'den aktardığı gibi; yeni süreçle birlikte, üretim araçları artık ne tarım toplumunun toprağı, ne de sanayi toplumunun sermayesidir, yeni üretim aracı bilgidir. Artı değerin emek ve sermayeyle yaratılamayacağını savunan Drucker, bunun bilginin bilgiye uygulandığ 1 verim ve yenilikle meydana getirilebileceğini ortaya koymakta, bu yeni sürecin, temel aktör olarak da bilgi işçisini ön plana çıkardığını söylemektedir. Bu yeni sınıf içinde bilgi yöneticileri, bilgiyi verimli kullanabilenler olacak; bunlar, hem üretim olanakları, hem de üretim araçlarını ellerinde bulunduracaklardır. 
Dolayısıla Drucker'e göre, yeni sürecin temel ekonomik sorunu, bilgi işçisi ve bilgi işinin verimliliğidir (Aydınlı, 2004: 6).

Tüm bunların yanı sıra Fordist sistemin uluslararası ticarete yeterince yatkın olmamas1, üstelik küreselleşme olgusunun tartışıldığı o dönemde, diğer ülkelerin ihtiyaçlarına uygun üretimin gerçekleştirilememesi gibi durumlar tüm eleştirilerin odağında yer alıyordu. Küreselleşme kavramı sadece iktisadi meselelere içkin bir konu olmakla kalmamakta ve en başta devletin dönüşümü adına önem arz etmekteydi. Devlet, ekonominin en önemli aktörü olmaktan çıkarılıp klasik liberalizmin tarif ettiği, yani asayişi sağlayan rolüne geri dönmeliydi. Bununla birlikte olabildiğince küçülüp elinde bulundurduğu işletmeleri, özelleştirmeli dolayısıyla piyasa-devlet düalizmini sonlandırmalıydı. Aslında bu durum bildiğimiz anlamda ulus-devlet kavramının da değişmesi anlamına gelmekteydi. İçke, Engin ve Kızılkaya da aynı duruma dikkat çekerek küresel rekabetin içerdiği yenidünya düzenini Atzmüller'den şöyle aktarmışlardır:

"Postfordizme geçiş sürecinde devletlerin bir takım temel dönüşümleri yaşaması gündeme gelmektedir. Bunun altında, yeni kamusal görevlerin ve politik alanların yaratılmasi yoluyla kapitalist üretim ilişskilerindeki yenilik ve değişim kabiliyetinin güvence altına alınma arzusu yatmaktadır. Değişim kabiliyeti ve yenilikçi girişimcilik olgularının önem kazanmasının, aralarında teknoloji ve yapısal politikaları sayabileceğimiz bir dizi kamusal stratejiye yansiması söz konusu olmaktadır. Küresel rekabet gücüne odaklanan söz konusu yeni politika anlayışı, makroekonomik politikalarla yöneten ve talep odaklı Keynesyenci Refah Devleti anlayışının sonu olarak görülmektedir. Keynesyenci Refah Devletinin özelliği, uluslararası ekonomik iliş̧kileri ve sosyal hâsılanın yeniden bölüşümünü büyük ölçüde kontrol edebilme gücüne sahip olabilmesi olmuştur. Ne var ki, II. Dünya Savaşı sonrast yapılanan Keynesyenci Refah Devletinin karakter ve işlevleri 1970'li yıllardan sonra, temel bir takım dönüşümlere maruz kalmıştır." (İçke, Engin, Kızılkaya, 2012: 2).

Tüm bu gelişmelerin arka planında felsefi anlamda ciddi tartışmalar sürmekte, bu tartışmalar da özü itibarıyla modernite-postmodernite eksenli devam etmekteydi. Özellikle Fransa'da ortaya çıkan post-yapısalcı akımın eleştirileri ciddi karşılık bulmaktaydı. Post-yapısalcı akımdan özellikle Foucault ve Deleuze gibi düşünürlerin eleştirilerinin odağında zaten batı felsefesinde önemli yeri olan ereksel ve evrensel akıl vardı. Bu üretim biçimi ile somutlaşan ve de bürokrasizmin emrettiği, öznelerin de bunu yapmakla zorunlu olduğu dolayısıyla farklılıkları elemine etmeye yarayan bu zihin dünyası kıyasıya eleştirilmekteydi. Buna karşın örneğin Habermas gibi düşünürler, modernitenin yarattığı tahribatı kabul etmekle birlikte, felsefik olarak aklın, siyasal ve ekonomik olarak refah devletinin kazanımlarının göz ardı edilmemesi gerektiğini vurgulayarak, bir özeleştiri ile dönüşümün gerçekleşmesi gerektiğini söylemekteydiler. Habermas 1970'lerde yeni muhafazakârların refah devletine olan saldırılarına cevaben şunları yazar:

"Yeni muhafazakârlar, her ne pahasına olursa olsun iktisadi ve toplumsal modernleşmenin kapitalist modeline bağlı kalmak istiyorlar. Sosyal devlet uzlaşmasının geliştirdiği ve giderek de boğduğu ekonomik büyümeye öncelik tanıyorlar. Bu büyümenin sosyal açılan bütünleşmeyi bozucu sonuçlarına karşı, küçük burjuva bir kültürün, köklerinden koparılmış ama retorik olarak geri çă̆rılmış geleneklerine sığınmaya çalışıyorlar. 19. Yüzyılın sonundan bu yana iyi nedenlerle piyasadan devlete kaydırılan sorunların eski yerine kaydırılmasının, yani sorunların güç ve para araçları arasında ileri geri hareket ettirilmesinin bize ne gibi bir itilim vereceğini görmek zordur... Yeni muhafazakâr tarafin gelenekselci bir biçimde yakalamak ve hafifletmek istediği, yaşama evreninin sömürgeleştirilmesi deneyimleri, öteki tarafta radikal bir muhalefete yol açmaktadır" (Habermas, 2001: 20).

\section{Sonuç}

Sanayi devriminden bilgi toplumuna geçişin yaşandığı günümüze kadar toplumsal yaşamda ve dolayısıyla dünyada meydana gelen değişimlerin, işletmeler ve yönetim alanındaki gelişmelere bağlı olarak nasıl ve hangi boyutlarda etkilendiğinin incelendiği bu çalışmada, literatürde kabul 
görmüş yayınların taranması yoluyla veriler oluşturulmuş ve bu veriler ışı̆̆ında değerlendirmeler yapılarak birtakım bulgular elde edilmiştir. Elde edilen bulgular arasından çalışmanın amacına uygun olarak ulaşılan sonuçlar aşağıda sıralanmıştır:

- Bilimsel yönetim yaklaşımlarının temelinde yatan en az girdi ile en fazla çıktının alınması yani verimliliğin artırılması mottosu, fordist sistemde belki de had safhaya ulaşmıştır. Bu yeni süreçte çalışanlarının işletmeler içindeki yeri üretimin öznesi olmaktan çıkarak üretim faktörlerinden birisi haline gelmiş ve çalışanlar sistem içinde bir nesne haline gelmiştir. Diğer bir ifade ile işletme çalışanları, patronlar ve yöneticiler nazarında sahip oldukları beceri ve niteliklere göre sınıflara ayrılmış ve bu sınıflaşma toplumsal manada da karşılık bularak bir dehümanizasyon durumu ortaya çıkmıştır.

- Yönetim yaklaşımlarının ve fordist üretim sisteminin öncelediği en az enerji harcanarak en fazla işin yapılması ve bunun da en hızlı, en hatasız biçimde yapılması toplumsal yaşantıda da bir karşılık bulmuştur. Çalışma hayatında bu esas üzere kendisini dizayn eden insan, gündelik yaşamın her alanında daha pragmatik düşünen ve bunu hayatın merkezine alan standardize bir akı1 ya da düşünce sistemini benimsemek durumunda kalmıştır.

- İşletmeler daha kısa dönemlerde daha fazla üretim yaparak toplum ihtiyaçlarına daha hızlı yanıtlar üretebilme amaçları doğrultusunda, yalnızca gündüzleri değil akşam ve geceleri de vardiya usulü çalışma sistemleri geliştirmek durumunda kalmışlardır. Bu gelişmeler zamanla iş dışı yaşamda da, gecelerin de gündüzler gibi yaşanabileceği ve hayatın 24 saat devam edebileceği biçimde düzenlenmesine yol açmış ve günün her saatinin yaşanılabilir ve çalışılabilir hale getirilerek zamanın yeniden ve farklı bir düzlemde standardize edilmesi kaçınılmaz hale gelmiştir.

- Yönetimin bir bilim olarak sahneye çıkması ve sonrasında fordist üretim sistemine dayalı kitle üretim yapan büyük ölçekli işletmelerin ortaya çıkmasıyla beraber önceleri evlere yakın yerlerde bulunan küçük işyerleri artık giderek evlerden ayrı bölgelerde konumlanmaya başlamıştır. Dolayısıyla iş hayatı günlük yaşamdan izole bir nitelik taşımaya doğru evrilmiştir. Kitle üretimi ile beraber aynı türden büyük miktarlarda mal ve hizmet üretmeye yönelik olarak işletmeler ve fabrikalar standart tasarımlara yönelmeye başlamışlardır. İşletmeler ve fabrikalardaki bu mekânsal standartlaşma zamanla toplumsal hayatta da karşılık bulmuş ve insanların yaşam alanları olan konutlarda, eğlence mekânları ya da boş zaman değerlendirme mekânları gibi alanlarında da konseptleşmeye ve oluşturulan konseptlere göre de belirli düzeylerde standartlaşmalara gidilmeye başlanmıştır.

- Fordist sistemin üretimde verimliliği artırarak kitle üretimi gerçekleştirmesi, bir yönüyle de insan ihtiyaçlarını bireysel manada karşılamayı da imkânsız kılmaktaydı. Önceleri terzilere gidip vücut ölçülerine göre kıyafet yaptıran bireylere artık belirli beden aralıklarında standart modeller üretilmekteydi. Kitle üretiminin bu olumsuz tarafını bertaraf edebilmenin yolu olarak ise toplumlara yeni tüketim alışkanlıkları kazandırılarak kitle tüketiminin hâkim olması sağlanmıştır. Artık insanlar üretilen mal ve hizmetler arasından, genel ihtiyaçları optimal düzeyde karşılayabilecek biçimde tasarlanmış ama fiyat ve kalite açısından daha makul ve ulaşılabilir ürünlere yönelmeye başlamışlardır.

- İnsanların günlük yaşam standartlarının, çalışma alanlarındaki verimliliğini olumsuz yönde etkilemeyecek; tam tersine kapitalist sistemin sorunsuz yürümesine katkı sağlayacak alışkanlıklara hatta kimi zaman ritüellere dayandırılarak belirli kalıplara oturtulması da işletmeciler ve yöneticilerin yeni toplumsal yapı üzerine etkileri arasında yerini almıştır. İş dış1 yaşamda vaktinin çoğunu evinde geçirerek, ertesi güne daha iyi performans düzeyinde çalışabilecek biçimde uyanacak insan modeli işletmeler ya da sermaye sahipleri için arzu edilen bir durum, profesyonel iş yaşamında emeği ile var olan çalışanlar için ise yeni davranış kalıpları ve yaşam modeli anlamına gelmiştir. 
- İşletmelerin kapitalist düzen içerisinde varlıklarını sürdürebilmeleri için değişen dünyaya yaydığı bir diğer etki de kitle kültürünün oluşturulmasıdır. Bu sayede toplumların belirli sınıflara göre şekillenmiş ve aynılaşmış kültürlere evirilmesi yoluyla benzer tüketim kalıplarına yönlendirilmesi; her bir sınıfa ait olan çalışanların üretilen kitlesel nitelikli mal ve hizmetleri kullanabilecek düzeyde bir gelire ve boş zamana sahip olacak biçimde iş ve çalışma koşullarına kavuşturulması amaçlanmıştır.

\section{Kaynakça}

Alp, S, (2009), Refah Devleti Düşüncesinin Gelişimi ve Bir Liberal Alternatif Olarak Üçüncü Sektör, Maliye Dergisi, 156 (Ocak-Haziran), 265-279.

Argın, Ş, (1992), Kapitalist Toplumda İşin ve İşgücünün Kaderi: Post-Fordizm, Birikim Dergisi, 41(Eylül), 16-29.

Aydınlı, H. İ. (2004). Sosyo-Ekonomik Dönüşüm Süreci (Post-Fordizm) ve Sanayi Ötesi Yaklaşımlar, Kamu-iş Hukuku ve İktisat Dergisi, 7(4), 79-98.

Belek, İ. (1999). Postkapitalist Paradigmalar, Sorun Yayınları

Buğra, A. ve Keyder, Ç. (2008). Sosyal Politika Yazıları, İletişim Yayınları

Dikmen, A. A. (2015). Makine, Işs, Kapitalizm ve Insan, Nota Bene Yayınları

Ertek, T. 2009). Makro Ikktisat, Beta Yayınevi.

Habermas, J. (2001). İletişimsel Eylemlilik Kuramı, (Çev: Mustafa Tüzel), Kabalcı Yayınevi

Harvey, D. (2003). Postmodernliğin Durumu. (Çev. Sungur Savran). Metis Yayınları

İçke, M. A., Engin, C. ve Kızılkaya, E. (2012). Refah Devletinden Rekabet Devletine Dönüşüm Tartışmaları, İstanbul Üniversitesi Siyasal Bilgiler Fakültesi Dergisi, 46(Mart), 1-24

Köse, A. H. ve Öncü, A. (2000). Kapitalizm, İnsanlık ve Mühendislik, TMMOB

Oskay, Ü. (2000). Yıkanmak İstemeyen Çocuklar Olalım, YKY

Saklı, A. R. (2007). Kapitalist Gelişim Sürecinde Fordizm ve Post-Fordizm, http://2015.ses.org.tr/wp-content/uploads/fordizmpostfordizm.pdf, (Erişim Tarihi: 5.6.2016)

Şan, M. K, . ve Hira, İ. (2007). Frankfurt Okulu ve Kültür Endüstrisi Eleştirisi, Sosyoloji yazıları I, (Sakarya Üniversitesi Sosyoloji Bölümü Ortak Çalışması) Kızılelma Yayınları, 324- 340.

Taymaz, E. (1993). Kriz ve Teknoloji, Toplum ve Bilim Dergisi, Say1: 56(61), 5-42.

Tunçer, P. (2012). Yönetin ve Organizasyon, Beta Yayınevi

Yentürk, N. (1993). Post-Fordist Gelişmeler ve Dünya İktisadî İşbölümünün Geleceği, Toplum ve Bilim Dergisi, Say1: 56, 42-58.

http://www.gutenberg.org/files/15776/15776-h/15776-h.htm (Erişim: 20.03.2020).

https://lean.org.tr/kitlesel-ve-yalin-uretim-sistemleri-arasinda-bir-karsilastirma/ 21.03.2020).

(Erişim: 